\title{
A silica long base tiltmeter with high stability and resolution
}

\author{
F. Boudin a) \\ Géosciences Montpellier, Place Eugène Bataillon, 34095 Montpellier, France \\ P. Bernard \\ Département de Sismologie, Institut de Physique du Globe de Paris, 4 Place Jussieu, \\ 7252 Paris Cedex 05, France \\ L. Longuevergne and N. Florsch \\ Sisyphe, Université Pierre et Marie Curie Paris VI, 4 Place Jussieu 7252 Paris Cedex 05, France \\ C. Larmat \\ Los Alamos National Laboratory, New Mexico 87545, USA \\ C. Courteille and P.-A. Blum \\ Département de Sismologie, Institut de Physique du Globe de Paris, 4 Place Jussieu, \\ 7252 Paris Cedex 05, France \\ T. Vincent \\ 4, Street Stimbach 68160 Saintes Croix aux Mines, France \\ M. Kammentaler \\ Hergauchamps 68160 Saintes Maries aux Mines, France
}

(Received 24 July 2007; accepted 9 December 2007; published online 31 March 2008)

\begin{abstract}
In order to be able to provide valuable data in multiparameter measurement field operations, tiltmeters need to have a noise level better or equal than $10^{-9}$ rad for a period range from a few minutes to a few years and a long term stability ranging from $10^{-7}$ to $10^{-8} \mathrm{rad} / \mathrm{yr}$. Tiltmeter measurements should also be as much as possible insensitive to thermal disturbances, by taking great care of the horizontality of the base line tube first. Secondly, thermal responses have been assessed. We also took great care of the coupling of our tiltmeters with the bedrock. We've designed a long base tiltmeter with sensors in silica which has a low dilatation coefficient. The linear variable displacement transducer is based on coil coupling (powered by an alternative voltage). Finally we show the results of two $100 \mathrm{~m}$ silica water tube tiltmeters which were installed in a mine in the French Vosges massif in the framework of a hydrology research project. These instruments show a remarkably good stability $\left(6.5 \times 10^{-9} \mathrm{rad} /\right.$ month) and a low noise level (of the order of $10^{-11} \mathrm{rad}$ ). Toroidal and spheroidal free modes of the Earth were observed after the two last major earthquakes on Sumatra. (c) 2008 American Institute of Physics. [DOI: 10.1063/1.2829989]
\end{abstract}

\section{INTRODUCTION}

The survey of deformations of the surface of the Earth is performed through gravimetric dynamic, global positioning system (GPS) (geodetic), or strain measurements (tiltmeter or strainmeter). Tiltmeters provide data that combines a dynamic information (instantaneous geoid) and a geometrical information (soil flexure). The interest of tilt or strain measurement was revived in recent studies about volcanic intrusions $^{1,2}$ in recent demonstrations of long or short period transient strain signals in both subduction zones, such as the Mexican zone and the Cascadian zone, or in extension zones, such as the Gulf of Corinth. ${ }^{3-7}$ Free oscillations of the Earth excited by major earthquakes have also been measured with tiltmeters. ${ }^{8,9}$ Moreover, tilt or strain measurements allow us to observe the crustal flexure which is produced by a large

\footnotetext{
${ }^{a)}$ Author to whom correspondence should be addressed. Fax: 0467143642 .
} Tel.: 04671436 85. Electronic mail: frederic.boudin@gm.univ-montp2.fr. range of loading processes, such as hydrological or atmospheric loadings, or the weight of the moving water column during tsunamis. ${ }^{10}$

Proposing a detailed process at the origin of transient events requires much more minute observations than are available today. Most of the predictions for the amplitude of these transient signals point out that very weak signals must be indeed detected. It is ever more difficult for the smallest events which could be numerous at depth. An instrumental resolution much better than $10^{-7}$ is required at least for the strain. This is clearly out of reach for both GPS and interferometric synthetic aperture radar (inSAR) approaches. Our objective is to obtain tiltmetric data with a resolution better or equal than $10^{-9} \mathrm{rad}$ and long term precision ranging from $10^{-7}$ to $10^{-8} \mathrm{rad} / \mathrm{yr}$. As tiltmeters are more sensitive to local heterogeneities when their base line is short, ${ }^{11}$ it seems necessary to build tiltmeters with a long base and a very good coupling with the rock at the ends. The main drawback of water tube tiltmeters is their sensitivity to meteorological parameters, especially to the local temperature variations 

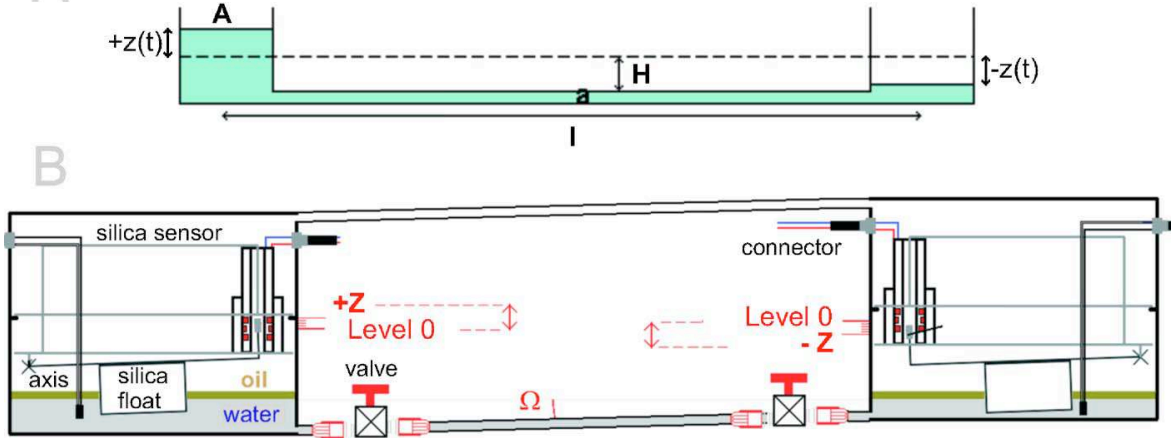

FIG. 1. (Color online) (a) Geometrical parameters of the instrument. (b) Schematic diagram of the long base silica tiltmeter presented in this paper. It is a fully filled water tube whose crucial components are made in silica to minimize temperature effects. The $\mathrm{T}$ connections between the vessel and the tube allow easy interventions or partial replacements. along the pipe which typically has a length of a few tens of meters to a few hundred meters. The goal of using a half filled tube decreases the instrumental sensitivity thermal variations. But in all cases the tube must be perfectly horizontal to minimize or remove the thermal sensitivity. It is possible to reduce the environment temperature variations by installing the instrument either deep in the ground (mine gallery) or buried just beneath the surface. ${ }^{5,7,8,12}$ The advantage of a tunnel mine is the very good thermal stability and the horizontality of their floor to build a horizontal pipe. In order to build just under the surface, one has to dig a nearly horizontal surface to install the tube. This can quickly become a constraining and expensive task.

\section{DESCRIPTION OF THE SILICA LONG BASE TILTMETER AND THE LVDT TRANSDUCER}

\section{A. Description of the long base tiltmeter}

The two long base tiltmeters which we will present are composed of two pyrex end vessels with an inner diameter of $132 \mathrm{~mm}$ and height of $165 \mathrm{~mm}$ [see Fig. 1(b)]. The connection between these pots is made by a polytetrafluoroethylene (PTFE) tube of $100 \mathrm{~m}$ length and with an inner diameter of $8 \mathrm{~mm}$ filled with distilled water. The connection between the end vessels and the tube is set by three way valves in $\mathrm{T}$ (the third extension is used for the filling of the tube with the fluid using a pump). The vessels are also connected with a polyvinyl chloride (PVC) tube in order to equalize the atmospheric pressure on the two liquid surfaces. To avoid water evaporation, we deposit on these two liquid surfaces a $3 \mathrm{~mm}$ thick layer of the silicone oil v100 Rhodorsil (which has a small thermal dilation coefficient). We take the additional precaution to heat the oil at a temperature of $130{ }^{\circ} \mathrm{C}$ for 5 days to eliminate all volatile elements. This silicone oil does not react chemically with water, Pyrex, silica, or PTFE and does not mix with water.

In each of the two vessels is inserted the sensor for the recording of the variation of the liquid height: it is a mono- lithic sensor designed almost entirely in silica [see Fig. 1(b)], with an effective range of $2.2 \mathrm{~mm}$. Translated in tilt measurement, the ranges are $440 \mu \mathrm{rad}$ for a $10 \mathrm{~m}$ long base and of $44 \mu \mathrm{rad}$ for a $100 \mathrm{~m}$ long tiltmeter. The sensor is made up of a mobile silica float fixed on the Pyrex vessel through three contact points. A very fine silica wire (diameter of a few microns) between two points on the armature has the function of rotation axis for a silica arm hooked to the float and has a ferrite at its end. The latter can move within a silica linear variable displacement transducer (LVDT), and its displacement produces a magnetic field variation which in turn creates an electrical current whose intensity is proportional to the tilt variation $\Omega$.

In order to perform thermal corrections, the temperature is measured with a PT1000 sensor. All wires (bringing electrical power or carrying measurements) go through a sealed panel of connectors (to allow easy disconnection) on the Pyrex vessel. The sealing is made by a joint of silicone. To check the quality of the sealing, we maintained a $30 \mathrm{kPa}$ pressure difference with the atmospheric ambient outside for 30 min. Each part of the instrument described above can be easily disconnected from the other. The $\mathrm{T}$ valves allow an easy repair without having to empty the tube.

\section{B. Principle of the LVDT transducer}

The LVDT inductive sensor is presented in Fig. 2(a). It is composed of a ferrite ( $\mathrm{Fr})$ moving inside a primary $(\mathrm{Pr})$ and two secondary (S1 and S2) coils. The ferrite is fixed on a silica stem $(\mathrm{Tg})$ hooked to the float. The three induction coils are rolled up around a silica chuck in three symmetrical furrows. This chuck is a transparent silica tube with an external diameter of $13 \mathrm{~mm}$ and an internal diameter of $5 \mathrm{~mm}$. Copper wire with a diameter of $0.08 \mathrm{~mm}$ is used for the coils (100 lathes for the primary coil and 300 for each secondary coil). These three induction coils are connected to an electronic board (developed by the electronics group of the seismological department of IPGP) which consists of an os-
A

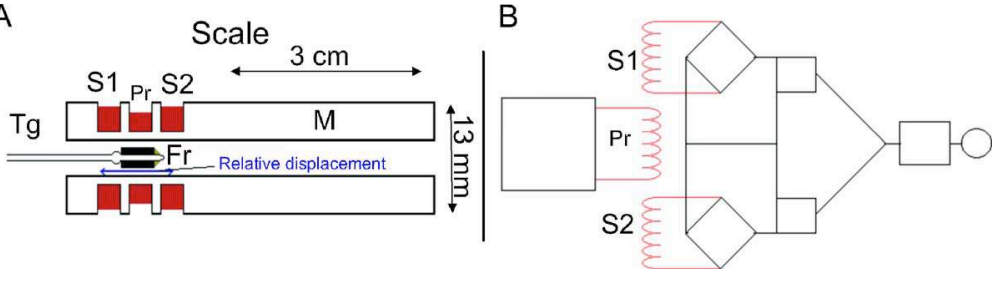

FIG. 2. (Color online) Schematic diagram of the silica LVDT transducer. The transducer measures the displacement of the ferrite by comparison of the degree of coupling between the two pairs of solenoids ( $\mathrm{Pr}, \mathrm{S} 1)$ and $(\mathrm{Pr}, \mathrm{S} 2)$. The input voltage and the analog computation of the difference between the two output voltages are performed by the CMS electronic card (b) which was developed and is currently built in the seismology department of IPGP. 


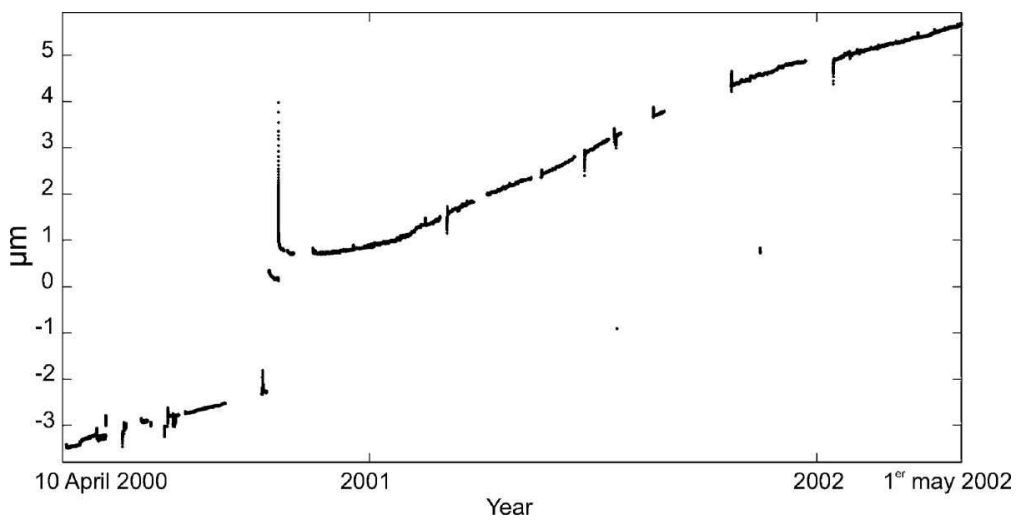

FIG. 3. Assessment of the long term stability of the silica LVDT transducer. In this sheltered site, the captor displays a monthly drift of $0.36 \mu \mathrm{m}$. cillatory generator and an electronic circuit which computes with great precision the difference of the voltages P-S1 and P-S2 [see Fig. 2(b)]. The primary coil is powered by a $500 \mathrm{kHz}$ oscillatory voltage alternating between $\pm 5 \mathrm{~V}$.

We consider the coil couples (Pr, S1) and (Pr, S2) as symmetrical transformers. When the ferrite is perfectly in the middle of the primary coil, the two transformers are equivalent. For a constant voltage (VP) applied at the primary coil, the two constant induced voltages VS1 and VS2 in the secondary coils are equal. If the ferrite moves closest to S1 (S2), the coupling ( $\mathrm{Pr}, \mathrm{S} 2)$ decreases (increases) compared to $(\mathrm{Pr}$, S1) according to the electromagnetic laws. The difference between the two voltages at secondary coils is thus proportional to the ferrite displacement. We checked that the sensor behaves linearly for a ferrite displacement between -2.2 and $2.2 \mathrm{~mm}$ (thus giving the range for our transducer). The advantage of this differential sensor is that any equal thermal or magnetic effects on both coils is theoretically eliminated. Moreover as the chuck is made of silica, the amplitude of the thermal dilation effects should be quite low. The primary power supply of a $500 \mathrm{khz}$ oscillator with alternating voltage gives another advantage. This system has a very small influence according to a possible variation of the continuous voltage. Moreover, these variations are stabilized by an electronic heard, the voltage is indeed stable as it is $10 \mathrm{~V} \pm 0.00003 \mathrm{~V} /{ }^{\circ} \mathrm{C}$.

\section{Long term stability of the LVDT transducer}

The instrumental stability of our long base tiltmeters strongly depends on the own stability of the LVDT transducer. The expression for the tilt measurement $\Omega$ is

$$
\Omega \approx \tan \Omega=\frac{Z_{2}-Z_{1}}{l},
$$

where $l$ is the base length and $\Delta z 2$ and $\Delta z 1$ are the liquid height variations in the vessels. If we suppose that there is no uncertainty on $l$, then the expression of the tilt uncertainty is

$$
d \Omega \approx \frac{\left|d z_{2}\right|+\left|d z_{1}\right|}{l} .
$$

In order to assess the internal drift of the LVDT transducer, we performed a test in collaboration with the laboratory of Rock Mechanics of the Polytechnic School of Paris. The experiment consisted in looking at the evolution of the transducer between April 2000 and June 2002. Each end of the transducer has been previously anchored to a silica device of a fixed length. The experiment site was chosen in order to have smooth and perfectly monitored temperature and humidity variations (40 $\mathrm{m}$ underground). Moreover, the LVDT sensors were protected by several antibug products. Over a 25 month period, an accumulated drift of only $9 \mu \mathrm{m}$ was recorded, that is to say, an average drift of $0.36 \mu \mathrm{m} /$ month (see Fig. 3). Notice that, if we remove the steps produced by our intervention in October 2000, the total drift would have been of a smaller value of $6 \mu \mathrm{m}$. Thus, this LVDT tranducer allows us to obtain a very small drift of only some nanoradians per month.

\section{Thermal sensitivity of the LVDT transducer}

During the same experiment described in the previous section, the LVDT transducer was subjected to temperature variations of a few ${ }^{\circ} \mathrm{C}$ over several days. These variations show a strong correlation with the drift measurement (see
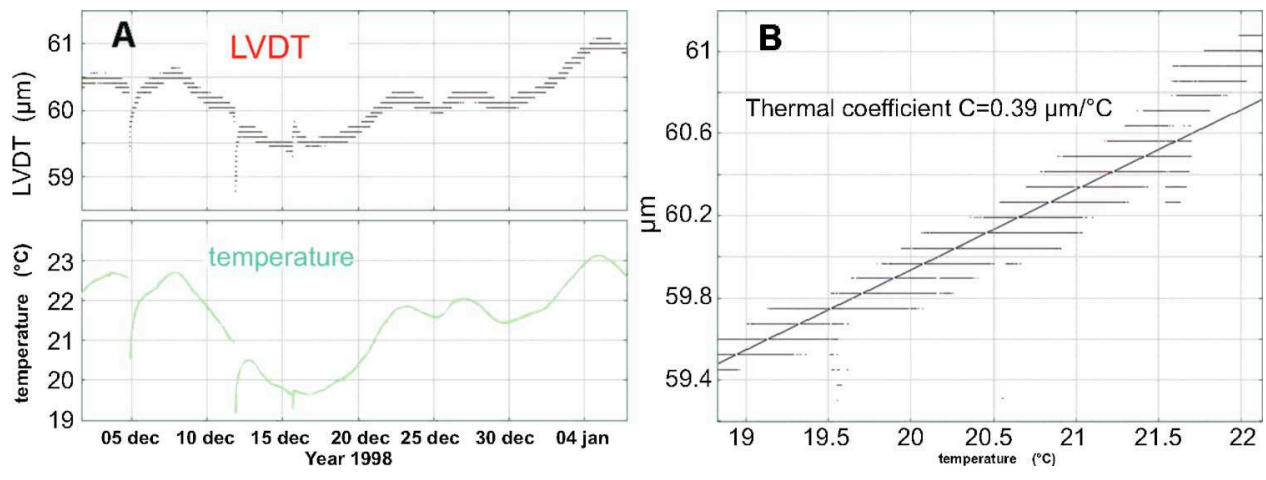

FIG. 4. (Color online) After removal of the average drift of the sensor, the measured variations are strongly correlated to the temperature variations (a). This allows us to device experimentally the thermal sensitivity of the LVDT transducer 
Fig. 4). The thermal sensitivity was estimated by the correlation coefficient and is $0.39 \mu \mathrm{m} /{ }^{\circ} \mathrm{C}=39 \times 10^{-8} /{ }^{\circ} \mathrm{C}$, which is a remarkably low value. As the characteristic length of the LVDT is of a the order of a few centimeters, we can notice that this coefficient is not of the same order of magnitude as the thermal dilation coefficient of silica: $54 \times 10^{-8} /{ }^{\circ} \mathrm{C}$. We think that the disturbance must be due to the electronics. As we have the objective to design an instrument as insensitive to the temperature as possible, we purposely proscribe as much as possible the use of metals which have got dilatation coefficients as much as 10 or 100 times larger than silica.

\section{INSTRUMENTAL RESPONSE AND SENSITIVITY}

\section{A. Equation of motion and transfer functions}

The dynamic behavior of the fluid is described by the Navier-Stockes equation,

$$
\left\lfloor\frac{\partial \mathbf{v}}{\partial t}+(\mathbf{v} \cdot \nabla) \mathbf{v}\right\rfloor=-\nabla P+\rho \mathbf{g}+\mu \nabla^{2} \mathbf{v} .
$$

As for the geometrical parameters of the instrument, $l$ is the length of the tube, $a$ and $A$ are the cross sections of the tube and vessels, respectively, $H$ is the fluid average height in the vessels, $g$ is the gravitational acceleration, and $\rho, v$, and $\mu$ are the fluid density, the kinematic viscosity, and the dynamic viscosity. $Z(t)$ is the vertical displacement in the vessel and $v(t)$ is the speed of a fluid particle [see Fig. 1(a)].

Equation (3) is integrated along a stream of current followed by a fluid particle, the left term becomes 0 and the right term gives the equation of motion,

$$
\left(2 H+l \frac{A}{a}\right) \frac{d^{2} Z(t)}{d t^{2}}+\left(\frac{8 \pi \nu l A}{a^{2}}\right) \frac{d Z}{d t}+2 g Z(t)=0,
$$

thus

$$
\frac{d^{2} Z(t)}{d t^{2}}+2 \beta \omega_{0} \frac{d Z(t)}{d t}+\omega_{0}^{2} Z(t)=0,
$$

with

$$
\omega_{0}^{2}=\frac{2 g}{2 H+l \frac{A}{a}} \approx \frac{2 g a}{l A}
$$

when

$$
2 H \ll \frac{l A}{a}
$$

and

$$
\beta=\frac{2 \pi \nu l A}{g a^{2}} \omega_{0},
$$

where $\omega_{0}$ is the eigenfrequency of the system and $\beta$ is the relative damping factor.

When the instrument is excited by external forces, such as a rotation versus the vertical $\theta(t)$ or a horizontal acceleration of the base $\ddot{X}(t)$, Eq. (3) becomes

$$
\frac{d^{2} Z(t)}{d t^{2}}+2 \beta \omega_{0} \frac{d Z(t)}{d t}+\omega_{0}^{2} Z(t)=-\frac{a}{A} \ddot{X}-\omega_{0}{ }^{2} \frac{l \theta}{2} \text {. }
$$

TABLE I. Inertial factor derived by different authors.

\begin{tabular}{lcc}
\hline \hline Assumption, method & Inertial factor & Study \\
\hline Lagrangian resolution & $2 H+\frac{4 l A}{3 a}$ & Shepard (1971), Agnew (1986), \\
& & d'Oreye (2003) \\
Eulerian method & $2 H+\frac{l A}{a}$ & Eaton (1959), \\
& & Horsfall (1977) \\
\hline \hline
\end{tabular}

Often, the fluid equation is solved by the Euler motion technique, ${ }^{11,13}$ which leads to this equation of motion but without the second member. On the other hand, Shepard ${ }^{14}$ found a slightly different result through the Lagrangian resolution of the system. He obtained an exact value for the inertia factor of $2 H+4 l A / 3 a$ instead of $2 H+l A / a$ (see Table I).

We assume a uniform velocity profile for our derivation of the inertial factor compared to the parabolic profile assumed by d'Oreye. ${ }^{8}$ However, as will be showed in the following sections, with the typical values of the parameters of presently operating tiltmeters, the difference in the inertia factor and thus in the transfer functions are insignificant.

Equations (5) and (7) are differential equations of second order with constant coefficients and with a second member for Eq. (7). By a Laplace transform two transfer functions are derived for the tilt, $T(\omega)$, and for the horizontal displacement, $D(\omega)$.

$$
T(\omega)=\frac{1}{-\frac{\omega^{2}}{\omega_{0}^{2}}+2 i \beta \frac{\omega}{\omega_{0}}+1}
$$

and

$$
D(\omega)=\frac{\frac{a \omega^{2}}{A \omega_{0}^{2}}}{-\frac{\omega^{2}}{\omega_{0}^{2}}+2 i \beta \frac{\omega}{\omega_{0}}+1} .
$$

These two transfer functions have two poles and two zeros,

$$
\omega_{\text {poles }}=\omega_{0}\left(\beta \pm \sqrt{\beta^{2}-1}\right)
$$

and

$$
\omega_{\text {zeros }}= \pm \infty \text {. }
$$

$D(\omega)$ has a supplementary zero at $\omega=0$.

The amplitude and the phase of $T(\omega)$ and $D(\omega)$ are represented in Fig. 5. We can notice that the long base tiltmeters are far from sensitive to the displacement component.

Tilt transfer functions can be measured experimentally by instantaneously adding some amount of liquid in one vessel. The response of the system $d(t)$ to this Heaviside excitation is measured. The step response $d(t)$ is related to the transfer response by

$$
T(\omega)=\omega_{0}^{2} \mathcal{F}\left[d^{\prime}(t)\right] .
$$

The experimentally derived transfer function can be compared to the theoretical prediction by of Eqs. (8) and (9). 

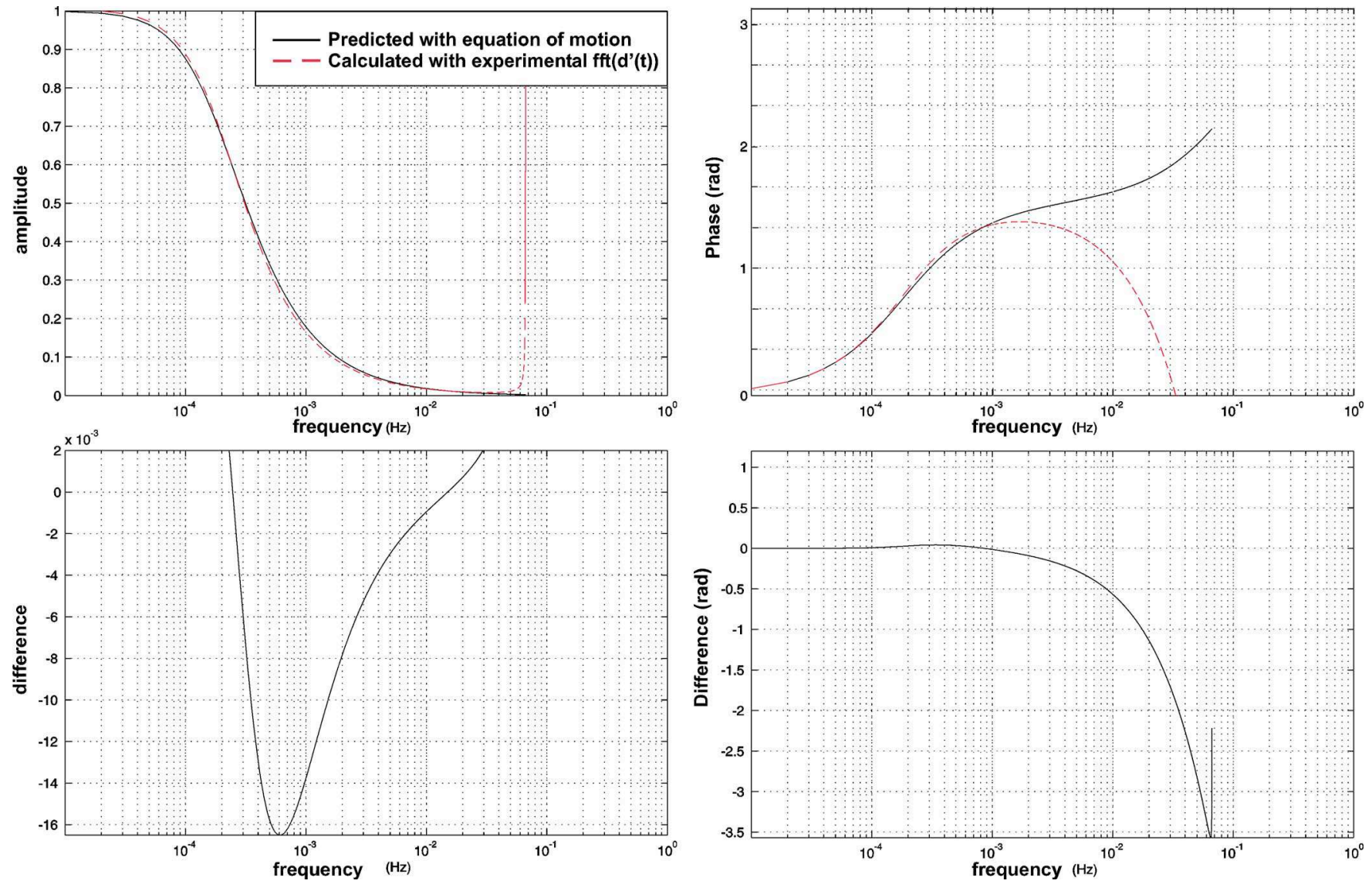

FIG. 5. (Color online) (Left) Theoretical (solid lines) and experimental (dashed lines) amplitude of $T(\omega)$. (Right) Theoretical (solid lines) and experimental (dashed lines) phase. (Bottom) Corresponding plot of the difference.

\section{B. Experimental calibration}

We did the measurement for each of the two transducers in order to have two independent estimations. The whole experiment had to be done quickly (a few minutes) in order to avoid notable variations of environment conditions such as the temperature.

The sensitivities of the sensors to incremental vertical displacement are defined as

$$
S 1=\frac{\Delta U 1}{\Delta Z 1} \quad \text { and } S 2=\frac{\Delta U 2}{\Delta Z 2} \quad \text { (where } \Delta U 1 \text { and } \Delta U 2 \text { are in volts and } \Delta Z 1 \text { and } \Delta Z 2 \text { are in micrometers). }
$$

The most delicate problem with this experimental assessment is the biases due to the presence of the menisci at the surface of the liquid. Capillarity effects along the pyrex-PTFE wall of the vessels can counteract the ascension of the liquid when injecting a small volume of liquid smaller or of the same order than the capillarity height [see Figs. 6(a) and 6(b)]. The solution advocated by d'Oreye ${ }^{6}$ is to add a sufficient amount to avoid these problems. Instead, we chose to use an oil with a capillarity height of $5.54 \times 10^{-4} \mathrm{~m}$, that is, approximately twice smaller than the one of water. Our sensor has the advantage of a sufficiently large range about $\pm 1 \mathrm{~mm}$ to do so. We thus decided to inject $1 \mathrm{ml}$ of liquid at each step which gives a variation of the liquid height of $73 \mu \mathrm{m}$ in the vessel. The accuracy about the volume of injected liquid is better than $2 \%$, which is then the assumed error in our calibration procedure. We perform the fluid injection over all the possible effective range measurement in order to have the largest possible number of measurements to minimize the estimation errors.

The slope in the linear part of the calibration curve gives the coefficient of calibration of the sensor (see Fig. 6). The experimental measurements show a remarkably small scattering around the average slope, which is determined by a linear regression on 30 points of measurement. The difference between the measured curve and the regression line are some oscillations with an eight or nine point period. They produce a standard deviation of $18.5 \mu \mathrm{m}$, that is to say, a calibration error of $4.1 \%$ on the $\mathrm{N} 37^{\circ} \mathrm{E}$ sensor and $3.7 \%$ on 

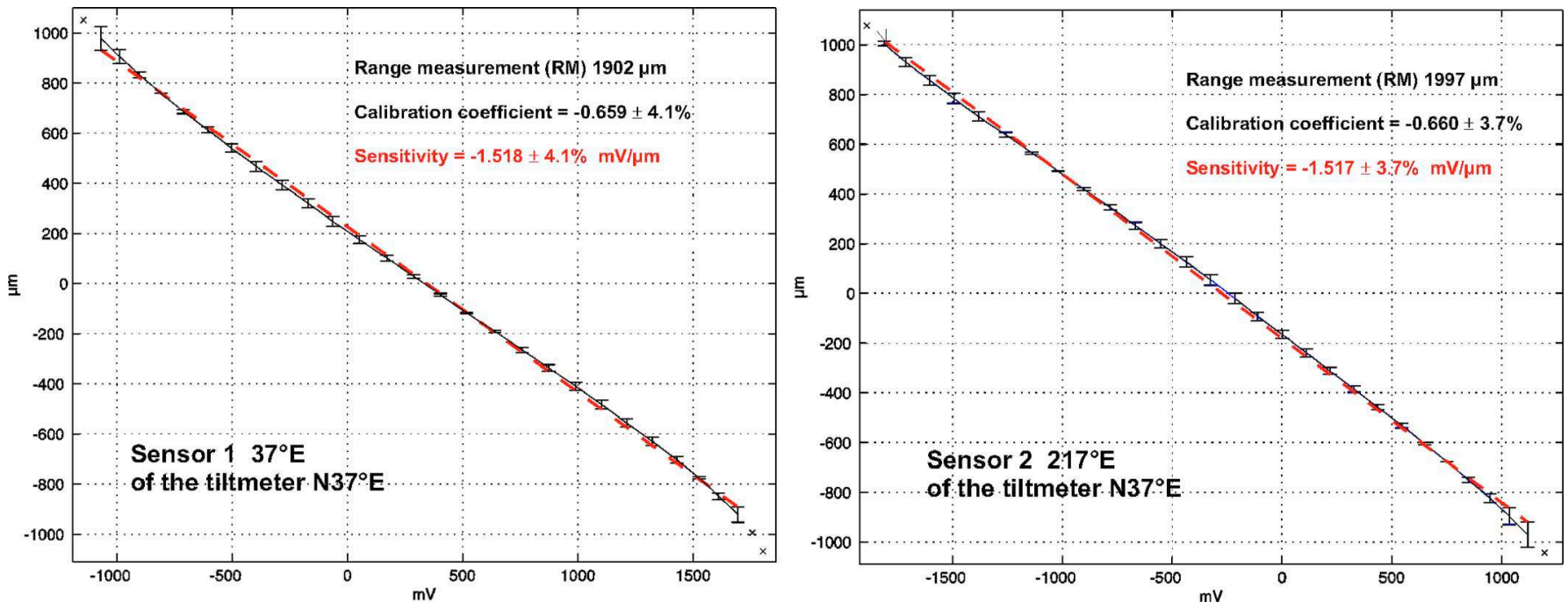

FIG. 6. (Color online) Calibration curves for the two sensors of the long base tiltmeter along the $\mathrm{N} 37^{\circ} \mathrm{E}$ direction. These curves were obtained experimentally by incrementally adding a small determined amount of liquid in each vessel $(1 \mathrm{ml})$.

the $\mathrm{N} 217^{\circ} \mathrm{E}$ sensor. These oscillations cannot be produced by a thermal dilation because of its magnitude. An increase of some tenths of ${ }^{\circ} \mathrm{C}$ in temperature (prompted by our presence) produces a variation of several micrometers and would thus correspond to an error of some tenths of percent in the calibration. We think that these oscillations are produced by capillarity effects and their eigenperiod corresponds to the capillary height of the oil. When cumulating the capillarity and injected volume errors, the total error of the calibration process can reach $6 \%$.

\section{RESULTS FROM A CONTINUOUS MONITORING WITH TWO $100 \mathrm{~m}$ LONG WATER TUBE TILTMETERS (STATION IN THE VOSGES MOUNTAINS)}

\section{A. The hydrology research project (ANR, ECCO 9 hydrology and geodesy)}

The hydrology research project which started at the end of the year 2004 aims to study the effect of the hydrological load of an aquifer in the Rhine Valley (Vosges) and the associated crustal flexure. In order to meet this objective, we need to be able to measure the strain with a high resolution and stability for time spans from few minutes to few years.
The site is a mine located $35 \mathrm{~km}$ eastward from the large Rhine aquifer and $1 \mathrm{~km}$ northward from a small river and its aquifer. We installed two $100 \mathrm{~m}$ long tiltmeters, one in the $\mathrm{N} 37^{\circ} \mathrm{E}$ direction which has provided continuous monitoring since December 2004 and the other in the radial direction which started in November 2005, near Sainte-Croix aux Mines. The geographical coordinates are (latitude: $48.27^{\circ} \mathrm{N}$, longitude:07.24 ${ }^{\circ}$ ). In Fig. 7, we can see a seasonal tilt of amplitude of several $10^{-7}$ rad produced by the hydrological state variation.

\section{B. Earth tide analysis}

The first tilt continuous monitoring started in December 2004 with the long base tiltmeter in the $\mathrm{N} 37^{\circ} \mathrm{E}$ direction. Over the first 28 months, we can observe very well the Earth tide signal (see Fig. 7). We conducted two analyses with the ETERNA software, in order to estimate the noise on different frequency bands near the Earth tide modes. The first analysis is over the first 14 months, and the second over 28 months. On the first analysis of semidiurnal and diurnal tides, the noise level is between 4.8 and $10.4 \times 10^{-11} \mathrm{rad}$, and on the second, longer analysis the noise level is smaller with

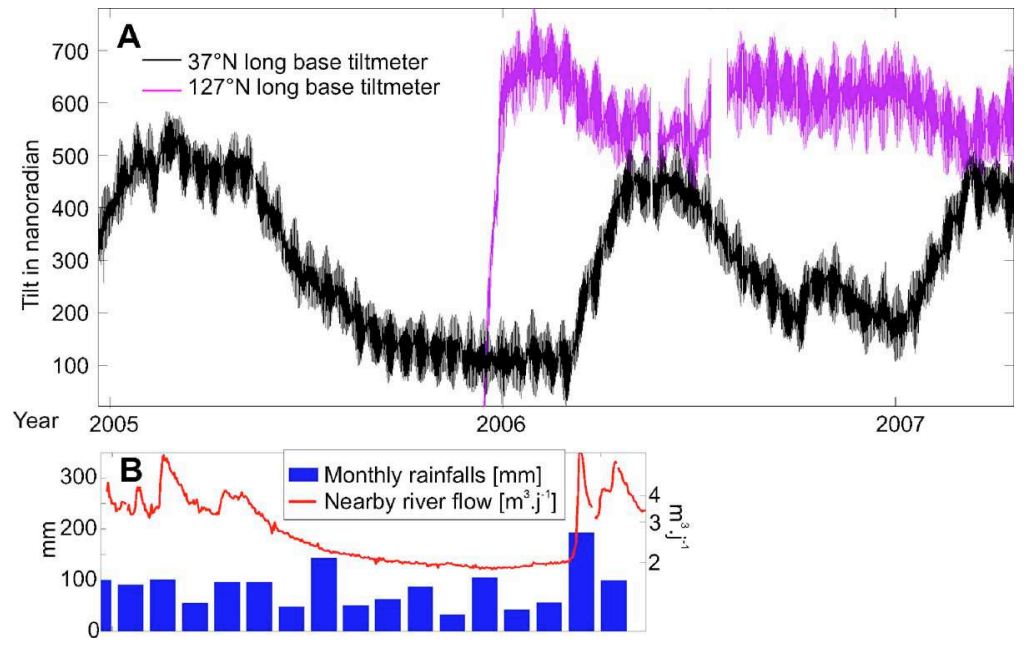

FIG. 7. (Color online) (a) Tiltmetric signal over the whole recorded period (December 2004-April 2007) measured in direction $\mathrm{N} 37^{\circ} \mathrm{E}$ and $127^{\circ} \mathrm{N}$. (b) The curve shows the long term flow of water in the mine, and the vertical bar shows the monthly rainfall. The tilt signal is a strain in the mine produced by the hydrological effect. 
TABLE II. On a duration 14 and 28 months, noise level on the frequency bands of the tide waves of the long base tiltmeter in direction $\mathrm{N} 37^{\circ} \mathrm{E}$.

\begin{tabular}{lccccc}
\hline \hline $\begin{array}{l}\text { Frequency band (cpd) } \\
\text { (cycle per day) }\end{array}$ & 1 & 2 & 3 & 4 & $\begin{array}{l}\text { White } \\
\text { noise }\end{array}$ \\
\hline $\begin{array}{l}\text { Noise (nrad) on } \\
\text { duration of 14 months }\end{array}$ & 0.104 & 0.048 & 0.030 & 0.031 & 0.035 \\
$\begin{array}{l}\text { Noise (nrad) on } \\
\text { duration of 28 months }\end{array}$ & 0.068 & 0.035 & 0.020 & 0.020 & 0.025 \\
\hline \hline
\end{tabular}

a value between 3.5 and $6.8 \times 10^{-11} \mathrm{rad}$. The white noise level was also assessed, with a very small value from 3.5 to $2.5 \times 10^{-11} \mathrm{rad}$. We also estimated the amplitude of the main semidiurnal wave M2. For our site of Sainte-Croix aux Mines (Vosges massif), in $\mathrm{N} 37^{\circ} \mathrm{E}$ direction, it is $27.58 \mathrm{nrad}$ with a very small $\mathrm{rms}$ from $24 \times 10^{-12}$ to only $18 \times 10^{-12} \mathrm{rad}$ and the uncertainty on phase is from $0.05^{\circ}$ to $0.037^{\circ}$ (that is to say, $4.5 \mathrm{~s}$ ). It is one of the best precisions recorded today with a tiltmeter and that on a recording duration of only 28 months. We look forward to the future results over several years of durations. We sum up these results in two tables: Table II shows the noise values by frequency bands and Table III shows the tidal wave amplitudes found with their uncertainties (rms).

Using the ETERNA software also allows us to compare the theoretical tides with our observations. In the following the $\gamma$ value refers to the amplitude ratio and $\varphi$ to the difference in phase. Tide signals were already measured in Western Europe with horizontal pendula by Melchior. ${ }^{15,16}$ The main conclusion of his study is that east-west (EW) observations are more easily predicted than north-south (NS) observations for which $\gamma$ values go from 0.38 to 0.9 . We found $\gamma$ values always lower than 1 , which can vary from 0.68008 for the $\mathrm{O} 1$ wave, 0.79892 for M2, and 0.86550 for the wave N2. Our instrument geographical coordinates are $48.27^{\circ} \mathrm{N}$ and $07.24^{\circ} \mathrm{E}$ and the base azimuth is $\mathrm{N} 37^{\circ} \mathrm{E}$ (closer to the NS direction than the EW direction). The station is far enough from any sea zones so as not to exclusively record
TABLE III. With the ETERNA software, on a 28 month duration, estimated amplitudes of the tidal waves in the tiltmetric signal in direction $\mathrm{N} 37^{\circ} \mathrm{E}$.

\begin{tabular}{lccccc}
\hline \hline Wave & $\begin{array}{c}\text { Amplitude } \\
\text { (nrad) }\end{array}$ & $\begin{array}{c}\text { Amplification } \\
\text { factor } \gamma\end{array}$ & $\begin{array}{c}\text { Stdv } \\
(\mathrm{nrad})\end{array}$ & $\begin{array}{c}\text { Phase } \\
\varphi(\mathrm{deg})\end{array}$ & $\begin{array}{c}\text { Stdv } \\
(\mathrm{deg})\end{array}$ \\
\hline Q1 & 1.6770 & 0.60596 & 0.0185 & -2.8698 & 1.0467 \\
O1 & 9.8306 & 0.68008 & 0.0238 & -0.9182 & 0.2033 \\
M1 & 0.8887 & 0.78209 & 0.0275 & -7.7945 & 2.2440 \\
P1S1 & 5.1637 & 0.76787 & 0.0328 & -3.1169 & 0.4741 \\
K1 & 15.999 & 0.78732 & 0.0302 & -4.5325 & 0.1377 \\
J1 & 0.7694 & 0.67685 & 0.0270 & -4.4642 & 2.9724 \\
O1N2 & 1.0966 & 0.82989 & 0.0121 & -11.1170 & 0.7062 \\
N2 & 7.1612 & 0.86550 & 0.0186 & -19.2627 & 0.1739 \\
M2 & 34.523 & 0.79892 & 0.0176 & -21.1816 & 0.0367 \\
L2 & 0.8305 & 0.67995 & 0.0115 & -17.3544 & 1.1641 \\
S2 & 13.661 & 0.67959 & 0.0141 & -18.7123 & 0.0866 \\
K2 & 3.8707 & 0.70860 & 0.0113 & -19.8017 & 0.2359 \\
M3M6 & 0.4780 & 0.8482 & 0.0101 & -4.2575 & 1.4274 \\
\hline \hline
\end{tabular}

oceanic load effects. d'Oreye ${ }^{8}$ also made an analysis of the tide signal recorded at Walferdange (Luxembourg) by a long base tiltmeter with an azimuth of $\mathrm{N} 27^{\circ} \mathrm{E}$ (close to our instrument). By also using the ETERNA software, he found $\gamma$ values for the M2 wave of $0.76522,0.83924$ for N2, and 0.67022 for $\mathrm{O} 1{ }^{8}$ His values are close to our estimates with a few percent discrepancy. Nevertheless, they are also always lower, which can be explained by a stronger oceanic load effect given the fact that their instrument is closer to the North Sea. He then applied an oceanic load correction to the theoretical assessments and found $\gamma$ values for the wave M2 of $0.8448,0.8832$ for $\mathrm{N} 2$, and 0.6563 for $\mathrm{O} 1$. There remains a discrepancy of $12 \%-16 \%$ for the semidiurnal tides. In our case, the discrepancy amounts to $14 \%-21 \%$ for the semidiurnal tides, and can be mostly accounted for by oceanic load added to the calibration error $\left(6 \%\right.$, Sec. III). ${ }^{17}$

\section{Long term stability}

In order to be relevant long term hydrological surveys, our instruments must display the smallest drift rate possible.

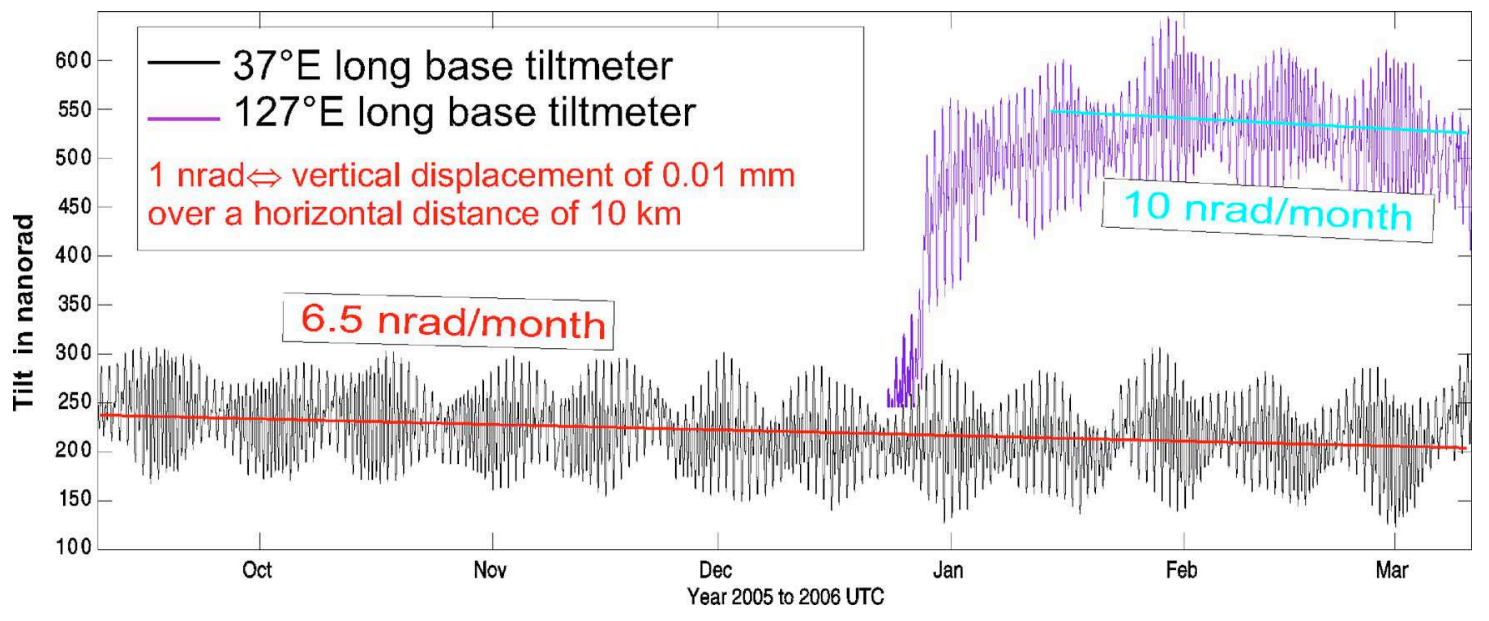

FIG. 8. (Color online) In dark, recorded signal by the first radial tiltmeter in direction N37 $\mathrm{E}$ between September 2005 and March 2006 . In gray, recorded signal by the tangential tiltmeter, one month after its installation, until March 2006. The small diurnal and semidiurnal oscillations are produced by the Earth tide. For the instruments in $127^{\circ} \mathrm{N}$ direction, the first month of measurement, it seems that one observes a drift produced by the stabilization of the rock coupling. But in the next months, in particular, here over the last 6 months of record, the drift (or perhaps a tiltmetric variation) is only between 6 and $10 \times 10^{-9} \mathrm{rad} / \mathrm{month}$. 


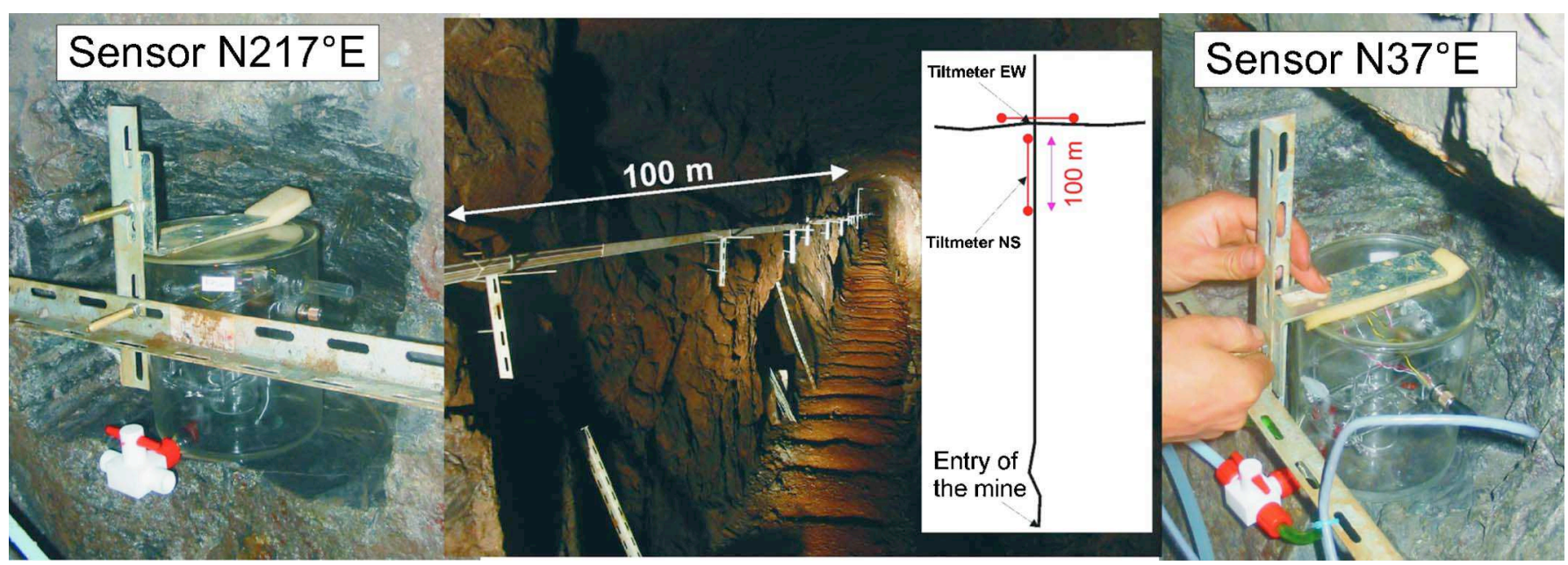

FIG. 9. (Color online) The $100 \mathrm{~m}$ long base tiltmeter N $37^{\circ} \mathrm{E}$ in a $600 \mathrm{~m}$ length gallery. (a) Picture of the sensor more in the south. (c) Picture of the sensor more in the north. (b) Picture of the tube connecting these two sensors. This one is perfectly horizontal and fixed along the wall of the gallery. A map of the gallery is also displayed.

Over the last months, the data showed a drift of only 6.5 $\times 10^{-9} \mathrm{rad} /$ month (see Fig. 8) (moreover a part of this dritft might be due to a constant very long period external tilt signal). We point out that $1 \mathrm{nrad}$ corresponds to a height of only $0.01 \mathrm{~mm}$ over a distance of $10 \mathrm{~km}$. This long term stability which was displayed very shortly after the installation $\left(1\right.$ month for the instrument $\left.127^{\circ} \mathrm{N}\right)$ is one of the lowest drift rates reported in the worldwide scientific literature. This proves that our long base tiltmeter with similar installation conditions is perfectly suitable for the monitoring of long term tiltmetric rates lower than $10^{-7} \mathrm{rad} / \mathrm{yr}$. Over a few years duration, this type of instrument would thus be able to resolve vertical tectonic or volcanic loads better than current GPS systems. On shorter durations of a few days to a few weeks, the detection capacities of long period signals will be better by a factor of 10-1000 than GPS resolution.

During the installation, the greatest precautions must be taken for three fundamental points. In order to have the best stability, we must carefully select and be sure of the neatness of the sensitivity sensors measuring the incremental liquid height. Sensors must sit on a perfectly flat rock plane for a good coupling between the bedrock and the sensors [Figs. 9(a) and 9(c)]. We thus had to dig niches within the walls. Finally, in order to have the smallest biases due to barometric and thermal perturbations, the tube must be as horizontal as possible [Fig. 9(b)].

\section{Observation of two large Sumatra events (2004 and 2005) and of the Earth eigenfrequencies}

Large earthquakes $(M>8)$ are required to excite at a perceptible level the lowest toroidal and spheroidal modal oscillations of the Earth which involve a whole deformation of the Earth mantle (see Fig. 10). For the $\mathrm{Mw}=9.3$ Sumatra event, we computed the spectrum of time series of $33.5 \mathrm{~h}$ of our $100 \mathrm{~m}$ long tiltmeter oriented along $\mathrm{N} 37^{\circ} \mathrm{E}$ and of
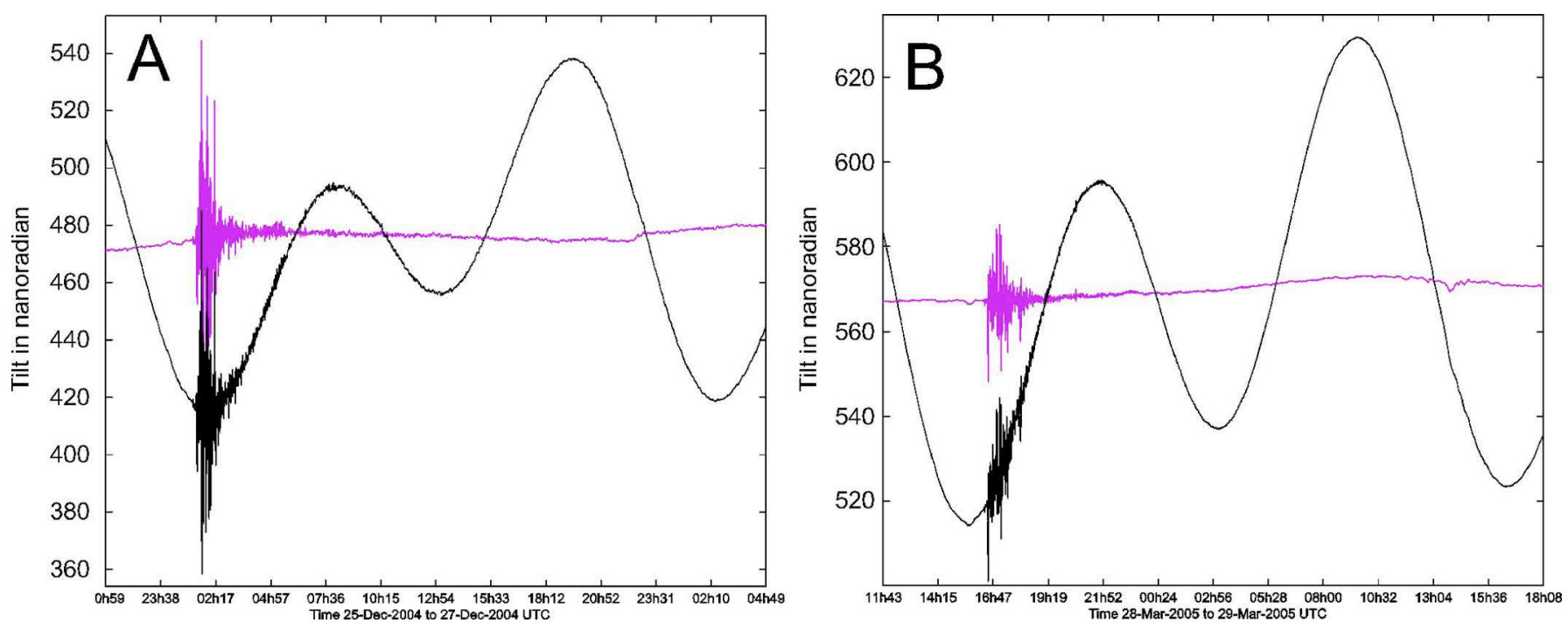

FIG. 10. (Color online) (a) Observation on the 26th of December 2004 of the Mw=9.3 Sumatra earthquake. (b) Observation on the 28th of March 2005 of the $\mathrm{Mw}=8.7$ Sumatra earthquake. The NS tiltmeter raw data are shown in dark and in gray after removal of the tide signal by an analysis with ETERNA software. 


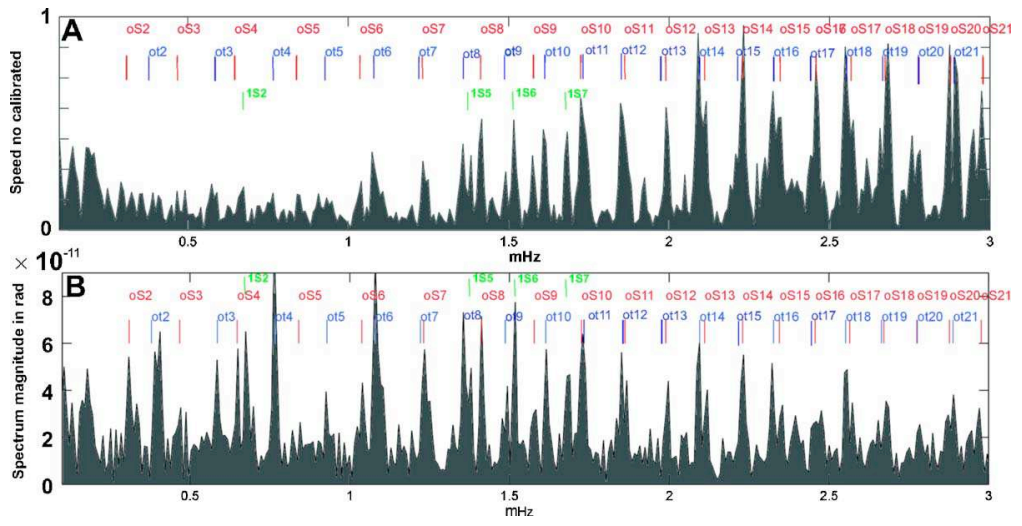

FIG. 11. (Color online) (a and b) Observation of the sphéroidal modes and toroidal modes. (a) Recording of the $\mathrm{N} 37^{\circ} \mathrm{E}$ speed component (not calibrated) of the STS1. (b) Observation on the tiltmeter component.

the STS1 of the seismic GEOSCOPE station of Échéry. For comparison, the two horizontal components of the latter were combined to give the component on the same $37^{\circ} \mathrm{E}$ direction (see Fig. 11). The very low level noise $\left(10^{-11} \mathrm{rad}\right)$ of both instruments allow the detection of all modes with frequencies down to $1.2 \mathrm{mHz}$. For the lowest frequencies, only the long base tiltmeter perceives the lowest modes down to the notable 0S2 for a series of $33.5 \mathrm{~h}$. Paradoxically, our instrument was not designed for this kind of observations as shown on the instrumental response curves on the left: $50 \%$ of the signal was filtered out by the instrument on the frequency band between 0.1 and $1.5 \mathrm{mHz}$ and the filter was up to $90 \%$ for frequencies higher than $2 \mathrm{mHz}$. Our numerical model of the instrumental responses shows that a tiltmeter with a larger tube diameter will be more appropriate for this kind of leading edge seismic observations (see Fig. 12).

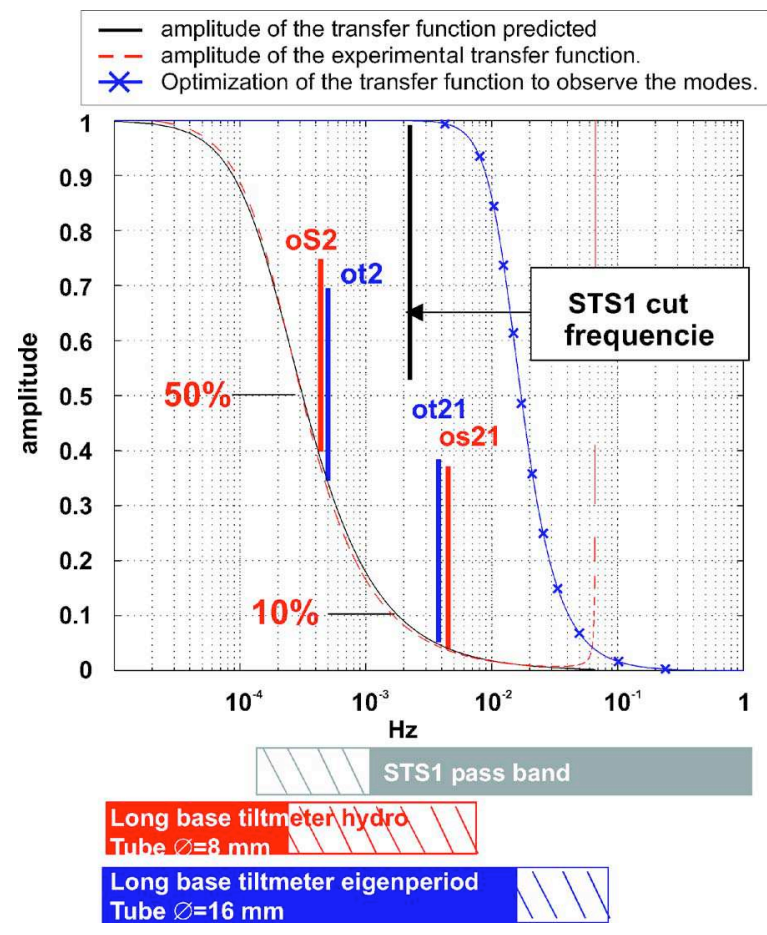

FIG. 12. (Color online) Comparison of the amplitude response between the $\mathrm{N} 37^{\circ} \mathrm{E}$ instrument with a diameter tube of $8 \mathrm{~mm}$ with a virtual instrument having a diameter tube of $16 \mathrm{~mm}$ for the observation of the OS2, OT2 until OS21 and OT21 free modes.

\section{E. Noise level and resolution}

The noise level on the frequency band of Earth tides was estimated by using ETERNA software, and also on the frequency band of the Earth free modes (see Secs. IV B and IV D). In order to estimate the noise level on the other frequency bands, we compute the power spectral density (PSD). An estimate of the PSD of a time series $\left\{X_{i}\right\} i=1, \ldots, N$, with a sampling step $d t$ (in seconds) and $N$ samples is

$$
\operatorname{PSD}\left(\omega_{p}\right)=\frac{2.0}{2 \pi N}\left|\sum_{k=1}^{N} x_{k} e^{-i \omega_{p} k d t}\right|^{2}
$$

for

$$
\left\{\omega_{p}\right\}=\left\{\frac{p}{N, d t} ; p=0, \ldots \ldots, \frac{N}{2}\right\} .
$$

The 2.0 in the numerator is for taking into account both negative and positive frequencies. ${ }^{8,13}$ We compare the PSD of our instrument with the long base tiltmeter at Piñon Flat Observatory (see Fig. 13).

\section{F. First order static thermal correction}

By increasing the length of the pipe the tiltmeter has a longer base, which increases its sensitivity and its stability, but it can also increase its thermal sensitivity.

Our thermal dynamic model ${ }^{7}$ shows that a local temperature disturbance on the fill water tube produces a dilatation of the liquid and the tube. When the tube is tilted, this disturbance generates asymmetrical liquid height variations at the end vessels (due to pressure interaction). As the tilt is determined from the level difference, an error on the tilt measurement is created in this case. Purely symmetrical height variation (only due to dilatation effect) is only possible when the tube is perfectly horizontal.

But it is an important constraint to install a perfectly horizontal tube. A good alternative is to work with half filled tubes, thus the liquid necessarily has a horizontal free surface all along the tube. ${ }^{4,12}$ On the other hand, there is a larger risk of evaporation and it is more difficult to know the transfer function. The other constraint is to have a perfectly straight installation; it is possible to build on the surface which is not always in deep mine. 


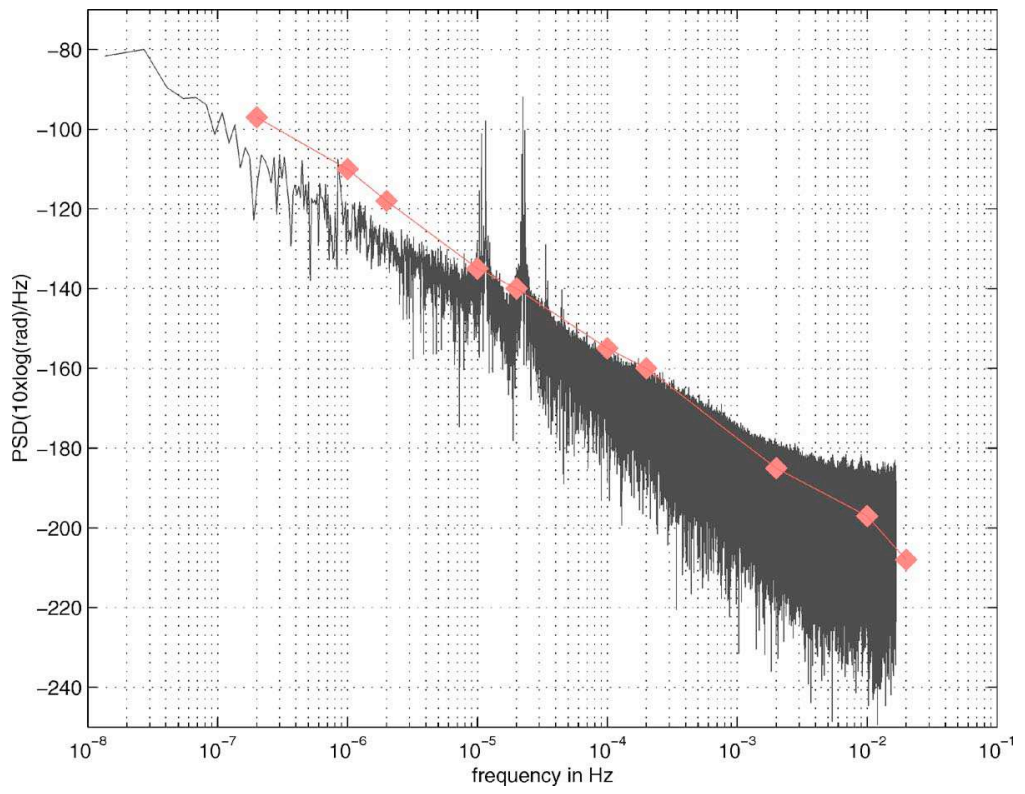

FIG. 13. (Color online) Comparaison between the power spectral density resulting from 28 months of recording data with the instrument in $\mathrm{N} 37^{\circ} \mathrm{E}$ direction (black curve) with the power spectral density reference coming from Agnew (1986) (dot).

In order to avoid assymetrical thermal effects, we took great care to have a perfectly horizontal pipe (with an error lower than $5 \mathrm{~mm}$ out of $100 \mathrm{~m}$ ). Moreover, the greatest thermal variations in the mine are annual and homogeneous with an amplitude of only few hundredths of ${ }^{\circ} \mathrm{C}$. With these conditions, the thermal influence is negligible. We also have to check the symmetrical effect of the temperature variations.
Each time someone passes along the tube, one creates a thermal wave (see Fig. 14). The latter heats the whole tube and produces a larger dilation of the PTFE tube than the liquid. We observe variations which are symmetrical and negative at the end vessels, but as they are perfectly symmetrical, they cancel out when doing the difference for the computation of the tilt signal.
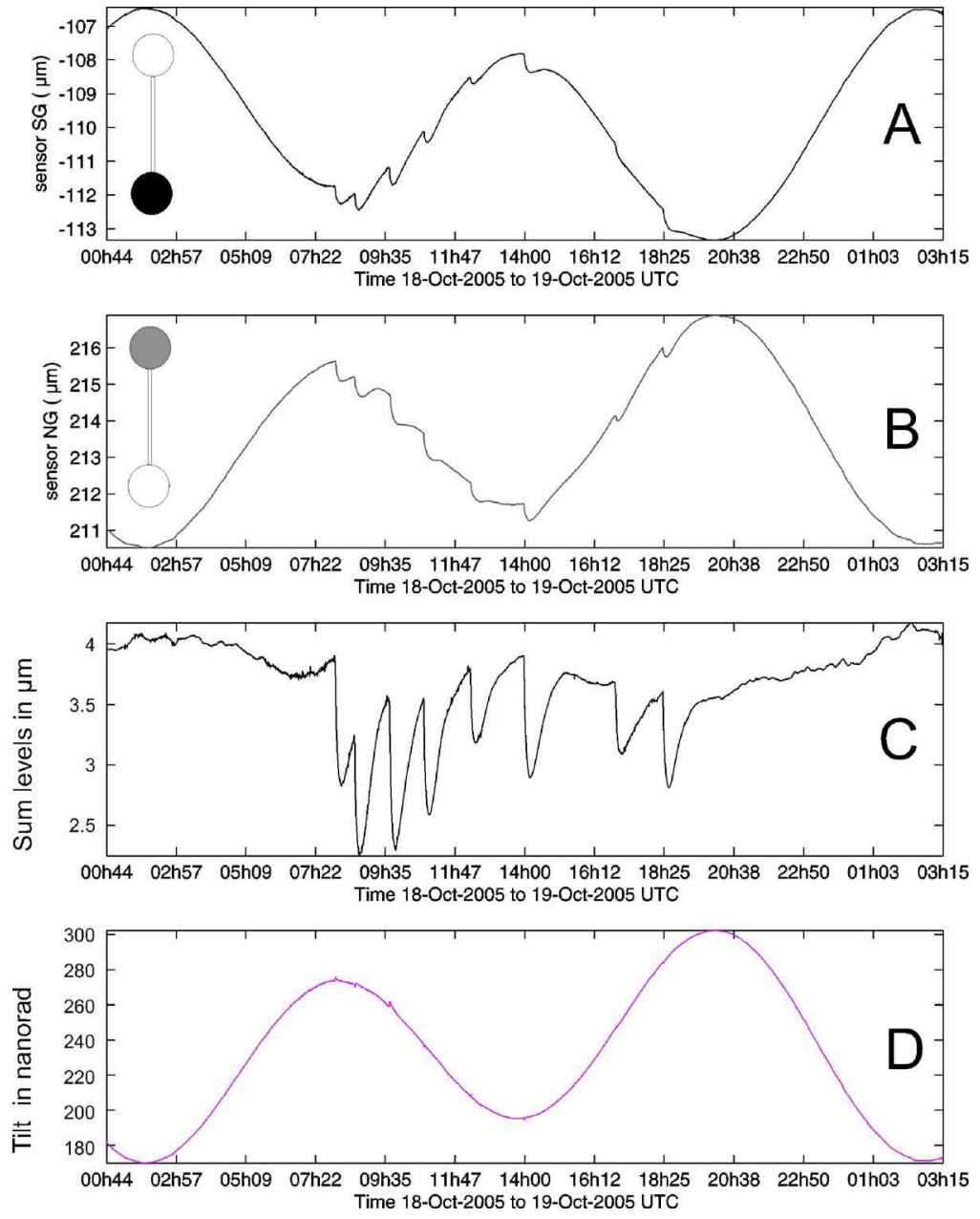

FIG. 14. (Color online) (a and b) Thermal disturbance produced by the tube and liquid dilation and observed at the two end vessels. The tube is perfectly horizontal and it is subjected over all its length to a thousandth heating of ${ }^{\circ} \mathrm{C}$. We observed the disturbance on the common mode [see Fig. 14(c)], but not on the differential mode which is proportional to the tiltmetric signal. [see Fig. 14(d)]. 


\section{CONCLUSION}

By years of experimentation, we have mastered in the know-how to build and install long base tiltmeters in all kind of areas where a crustal flexure signal needs to be monitored. The kind of signal can be, for example, some aseismic strain in seismogenic zones (in subduction or extensional areas) or the dilatation signal associated to a magma chamber or the hydrological load. We have recently carried out this latter type of monitoring in the Vosges mountain range. We are currently able to set up one or more long base tiltmetric stations with a base from 10 up to $500 \mathrm{~m}$. Our tiltmeters display a remarkable stability compared to other documented instruments and tiltmeters; in particular, we observe a stability of $6.5 \mathrm{nrad} / \mathrm{month}$ for the period range from seconds to several months. This stability allows submillimeter measurements that are still not possible for GPS or inSAR surveys. For example, transient event detection and measurement will be possible with our tiltmeters, when this kind of observations is still scarce as it requires a fine and continuous monitoring with a high resolution. In spite of a transfer function not adapted for the seismic frequency range, the observation of toroïdal and spheroïdal Earth normal modes has been possible with our operating instruments today. It is possible to design future instruments with adjusted geometrical characteristics which will have a better sensitivity in the seismic frequency range. We are also able to appreciably decrease the static thermal influence by installing a horizontal tube. However, we think that this induces an important technical constraint. It would be necessary to find the thermal dynamic response of an instrument with no horizontal tube and to try and correct it by identification.
${ }^{1}$ J. Battaglia, K. Aki, and J.-P. Montagner, Geophys. Res. Lett. 27, No. 5, 605 (2000).

${ }^{2}$ G. S. Mattioli, B. Voight, A. T. Linde, I. S. Sacks, P. Watts, C. Widiwijayanti, S. R. Young, D. Hidayat, D. Elsworth, P. E. Malin, E. Shalev, E. Van Boskirk, W. Johnston, R. S. J. Sparks, J. Neuberg, V. Bass, P. Dunkley, R. Herd, T. Syers, P. Williams, and D. Williams, Geology 35, 25 (2007).

${ }^{3}$ S. I. Franco, V. Kostoglodov, S. K. Singh, K. M. Larson, V. C. Manea, M. Manea, and J. A. Santiago, Earth, Planets Space 57, 973 (2005).

${ }^{4}$ T. Melbourne, R. Flake, M. Santillan, M. Miller, W. Szeliga, R. Bilham, and N. Suszek, High-resolution imaging of the anticipated 2005 Cascadia ETS slip transient, AGU, 2005.

${ }^{5}$ P. Bernard, F. Boudin, S. Sacks, A. Linde, P.-A. Blum, C. Courteille, M.-F. Esnoult, H. Castarède, S. Felikis, and H. Billiris, C. R. Geoscience 336, 313 (2004).

${ }^{6}$ M. J. S. Johnston, R. D. Borcherdt, A. T. Linde, and M. T. Galadwin, Bull. Seismol. Soc. Am. 96, 56 (2006).

${ }^{7} \mathrm{~F}$. Boudin, "Développement et validation d'un inclinomètre longue base de subsurface à silice et mercure: Application à des mesures géophysiques de haute résolution sur le chantier pilote du Golfe de Corinthe," Ph.D. thesis, Université Paris 7, 2004.

${ }^{8} \mathrm{~N}$. d'Oreye, "Inclinomètre à niveau hydrostatiques de haute résolution en Géophysique," Ph.D. thesis, Université Catholique de Louvain, Luxembourg, 2003.

${ }^{9}$ N. d'Oreye and W. Zürn, Rev. Sci. Instrum. 76, 024501 (2005).

${ }^{10}$ X. Yuan, R. Kind, and H. A. Pedersen, Geophys. Res. Lett. 32, Li5308 (2005).

${ }^{11}$ J. Horsfall, "A new Geophysical Tiltmeter," Ph.D. thesis, University of Cambridge, 1977.

${ }^{12}$ V. Kostoglodov, R. Bilham, J.-A. Santiago, V. Manea, M. Manea, and V.-R. Hernandez, Geofis. Int. 41, 11 (2002).

${ }_{13}^{13}$ J. P. Eaton, Bull. Seismol. Soc. Am. 49, 301 (1959).

${ }^{14}$ D. Shepard, "Dynamic Analysis of a Mercury Tiltmeter," Drapier Laboratories Report No. E-2598, 1971.

${ }^{15} \mathrm{P}$. Melchior, Proceedings of the Seventh International Symposium on Earth Tides, Stuttgart, 1976 (unpublished), pp. 41-70.

${ }^{16} \mathrm{P}$. Melchior, The Tide of the Planet Earth, 2nd ed. (Pergamon, New York, 1983), pp. 641.

${ }^{17}$ D. C. Agnew, Rev. Geophys. 24, No. 3, 579 (1986). 